\title{
On the Cover of this Issue: Estimating Void Nucleation Statistics in Laser-Driven Spall by D.D. Mallick, J. Parker, J.W. Wilkerson, and K.T. Ramesh
}
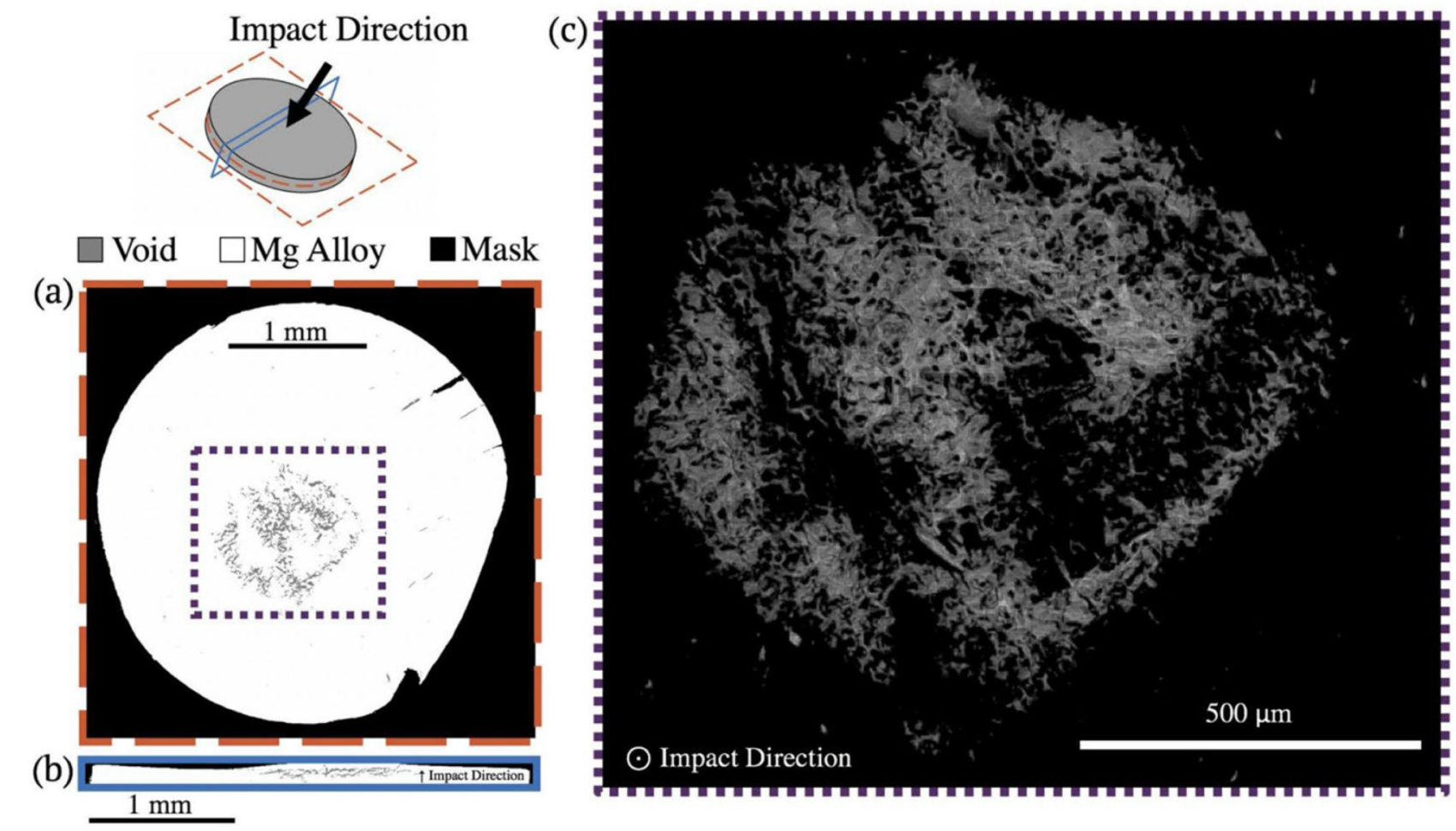

Estimating Void Nucleation Statistics in Laser-Driven Spall by D.D. Mallick, J. Parker, J.W. Wilkerson, and K.T. Ramesh

Publisher's Note Springer Nature remains neutral with regard to jurisdictional claims in published maps and institutional affiliations. 